\title{
Differences in swimming and diving abilities between two sympatric species of water shrews: Neomys anomalus and $N$. fodiens (Soricidae)
}

\author{
Helena MENDES-SOARES ${ }^{1,2}$ and Leszek RYCHLIK ${ }^{1,3}$
}

Helena MENDES-SOARES, ${ }^{1}$ Mammal Research Institute of the Polish Academy of

Sciences, Waszkiewicza 1, 17-230 Białowieża, Poland; ${ }^{2}$ present address: Department of

Biology, Indiana University, Bloomington, Jordan Hall A308, 1001, East Third St.,

Bloomington, IN 47405, U.S.A., e-mail: mhmendes@indiana.edu

Leszek RYCHLIK, ${ }^{1}$ Mammal Research Institute of the Polish Academy of Sciences,

Waszkiewicza 1, 17-230 Białowieża, Poland; ${ }^{3}$ present address: Institute of Environmental

Biology, Faculty of Biology, Adam Mickiewicz University, Umultowska 89, 61-614 Poznań,

Poland, e-mail: lrychlik@amu.edu.pl

19 text pages, 1 table and 4 figures

corresponding address:

Prof. UAM Dr. hab. Leszek RYCHLIK

Institute of Environmental Biology

Faculty of Biology

Adam Mickiewicz University

Umultowska 89

61-614 Poznań

Poland

e-mail: lrychlik@amu.edu.pl or rychliklesz@gmail.com

tel.: $(+4861)$ 829-57-51

fax: $(+4861)$ 829-56-36 


\section{Abstract}

2 Swimming and diving abilities of two syntopic species of water shrews, Neomys

3 anomalus and $N$. fodiens, were tested in aquaria using video-recordings taken from three

4 views (lateral distant, lateral close and dorsal). The frequency and total duration of diving,

5 as well as the mean duration of diving and floating bouts, were significantly higher in $N$.

6 fodiens than in N. anomalus. Frequency of paddling during surface swimming was lower in

$7 \quad N$. fodiens than in $N$. anomalus. $N$. fodiens dived mainly for long distances at the bottom of

8 the aquarium and performed a wider range of dive profiles than $N$. anomalus, which

9 preferred rather short and shallow dives. The two species differed also significantly in their

10 Fineness Ratios (describing how streamlined their bodies are) when diving. When

11 swimming, $N$. fodiens had a relatively wider body and performed narrower movements

12 with its tail than $N$. anomalus. These results show quantitatively and qualitatively for the

13 first time that $N$. fodiens is more proficient at swimming and diving than $N$. anomalus. The

14 results also help to explain the interspecific differences in efficiency of underwater

15 foraging, and support the idea of segregation of ecological niches of these species based on

16 their different foraging modes (diving vs wading).

17

18 Key words: foraging behaviour; interspecific competition; microhabitat selection;

19 underwater foraging; water shrews 
Neomys anomalus and Neomys fodiens are two species of water shrews that live mainly along small water courses and ponds, and in swamps and marshy meadows (Rychlik 2000). Although the distribution of $N$. anomalus may be conditioned by the presence of $N$. fodiens (Torre and Tella 1994; Kryštufek et al. 2000), they occur sympatrically and syntopically in many areas (Spitzenberger 1990, 1999; Rychlik 1997, 2000). Therefore, their ecological niches overlap in different dimensions (Rychlik 2000, 2005; Churchfield and Rychlik 2006) and they compete for food resources and life space (Rychlik 1997, 2004; Rychlik and Zwolak 2005, 2006). However, in many places they coexist for a long time, so some mechanisms separating their niches must be present.

Both species have morphological adaptations (feet and toes with fringes of stiff hairs, tail with keel, reduced ears, closeable nostrils) to their semi-aquatic life mode (Hutterer 1985; Pucek 1981; Churchfield 1998). The pelage of water shrews is also denser than that of terrestrial shrews and the awn hairs possess an H-shaped profile with lateral ridges filled with numerous ridges, which is believed to retain air, providing better insulation and buoyancy (Churchfield 1998). Although N. anomalus is strongly associated with water, its fringes of stiff hairs on the feet and the keel on the tail are less prominent than in N. fodiens (Pucek 1981; Churchfield 1998). In the wild, N. anomalus prefers places flooded with shallow water, whereas $N$. fodiens prefers those with direct access to streams and deep water (Rychlik 2000). The diet of N. anomalus is composed only or mostly of terrestrial prey (Niethammer 1978; Kuvikova 1985a, 1987; Churchfield and Rychlik 2006), whereas up to $95 \%$ of the diet of $N$. fodiens may be composed of aquatic prey (Niethammer 1978; DuPasquier and Cantoni 1992). All these attributes suggest better swimming and diving abilities in $N$. fodiens than in $N$. anomalus. investigated several times in N. fodiens (e.g. Ruthardt and Schröpfer 1985; Köhler 1991, 

underwater hunting tactics for this species: in open water for pelagic prey and at the bottom for benthic prey. $N$. fodiens was able to improve its food finding in underwater bowls and mazes through trial-and-error learning (Köhler 1993, 1996). Its maximal diving depth was $260 \mathrm{~cm}$ and the number of dives per day exceeded 520 (Vogel et al. 1998). Except for the work of Haberl (1993), these abilities had not previously been examined in $N$. anomalus, enhancing the need for the present study.

The aim of this work was, therefore, to analyse and compare qualitatively and quantitatively the swimming and diving behaviour of $N$. anomalus and $N$. fodiens in captivity. In the previous study (Rychlik 1997) it was shown that success and effectiveness of underwater foraging are higher in $N$. fodiens than $N$. anomalus. In the present study, we were interested in answering a question why the two species differed in success and effectiveness of underwater foraging, i.e. in finding mechanistic differences (e.g. in swimming velocity, stroking frequency, body inclination, fineness ratio or diving profiles) responsible for more efficient swimming and diving in one species than in another. For this purpose, simple experimental conditions (e.g. aquaria without resting places, aquatic prey or opportunity for spontaneous swimming) seemed to be good enough. We adopted the hypothesis that $N$. fodiens swims and dives more efficiently than $N$. anomalus and, based on theoretical works (Fish 1993b; Biewener 2003), tested the following predictions: (a) during surface swimming, the angle between the body and water surface will be smaller in $N$. fodiens than in N. anomalus, (b) velocity of swimming will be higher in $N$. fodiens, (c) body of $N$. fodiens will be more streamlined, (d) $N$. fodiens will generally spend more time diving, and (e) the duration of diving bouts will be longer in $N$. fodiens and they will swim a longer distance underwater. It was also assumed that the differences found would help to explain the mechanisms of resource partitioning and separation of ecological niches among these shrews. 
Tested animals (10 individuals of $N$. anomalus and 9 of $N$. fodiens; all subadult, i.e. fully grown but sexually inactive) were trapped in wet habitat around Białowieża village (Narewka River valley, eastern Poland) from August to November, 2003 and 2004. They were kept for 1 to 5 months in the laboratory of the Mammal Research Institute PAS (MRI) in Białowieża, under a natural light-and-dark cycle, $15-20^{\circ} \mathrm{C}$ and humidity ca. $80 \%$. Each shrew was kept in an individual cage $(38 \times 30 \times$ height $16 \mathrm{~cm})$ equipped with a shelter (reversed pot filled with moss) and litter (a mixture of sand, sawdust, peat, and moss). Water and food (minced beef, fly larvae, dried Gammarus sp.) were given ad libitum. Sample size was increased with 1 individual of $N$. anomalus and 3 of $N$. fodiens studied by LR in 1992 at the University of Osnabrück (Germany) under similar conditions of captivity and regime of handling and filming.

\section{Procedure of experiments}

Experiments were carried out between 16:00 and 20:00 in the laboratory, using two aquaria to analyse different behaviours. One large aquarium $(100 \times 30 \times$ height $40 \mathrm{~cm})$ was used for lateral distant and lateral close recordings, with the filming being done from one of the long sides of the aquarium. This aquarium had ca. $3 \mathrm{~cm}$ of pebbles on the bottom and a water depth of $25 \mathrm{~cm}$. The other aquarium $(60 \times 30 \times$ height $30 \mathrm{~cm}$; water depth 20 $\mathrm{cm})$ was used for dorsal-view recordings. Both aquaria had a $1 \times 1 \mathrm{~cm}$ grid on the background wall. The temperature of air and water was ca. $18^{\circ} \mathrm{C}$.

Experiments with each animal consisted of 1-5 trials (usually 5) and each trial consisted of three 5-minute recordings of the three different types performed in a random order. The animals were placed in the aquaria on a starting platform (a movable plastic shelf at one of the shorter sides) for 15-30 seconds, and were induced to swim by slowly lowering the platform under the water. Between the lateral distant and lateral close 
100 recordings, the animals were allowed to rest on the starting platform for approximately 2

101 minutes and given a small piece of minced meat (no food was in water). Between the

102 lateral and dorsal recordings, the shrews were transferred to their cages where they 103 remained from 30 minutes to a few days. To keep the water-repellent nature of the fur

104 intact, animals were carried in a wooden box or held by the tail with forceps (i.e. their fur 105 was not handled) during transfer to and from the test aquaria. This way, the animals' fur 106 was sufficiently dry on all the trials performed. Each animal was submitted to one trial per 107 day but was tested 1-5 times (usually 5 times during 5 successive days). Every few trials, 108 the walls of aquaria were cleaned and the water partially replaced.

109 The behaviour of the water shrews was recorded using a Digital Video Camera

110 Sony DCR-VX2000 E. The camera was programmed with AES program, a shutter speed 111 of 6000 and a manual focus of the closest views for better image quality. During filming, 112 two lamps of 75 and 150 watts were placed on the sides of the aquaria.

114 Data analysis

115 The recordings were transposed (with Broadway ver. 5.1 software) to digital format 116 (.jpg and .mpeg) and the files were analysed frame-by-frame (25 frames/sec) using Corel

117 Photo-Paint $9^{\circledR}$ and Corel Draw $9^{\circledR}$. The following categories of behaviour were 118 distinguished: (a) swimming - the animal actively used its paws to move on the water 119 surface; (b) floating - the animal stayed on the water surface but did not move or used its 120 paws only for balance; (c) diving - the animal moved with its whole body under water. The 121 following features of each behaviour were analysed from the different view recordings, 122 with an accuracy of $0.04 \mathrm{~s}$ ( 1 frame) for duration, $1 \mathrm{~cm}$ for distance and 0.1 degrees for 123 angle:

124 1) Lateral distant view: (a) proportion of behaviours - proportion of each behaviour 125 (floating, swimming and diving) in the total duration of the recording; (b) swimming speed 
126 - measured as the distance swam by the animals during 1 second; (c) diving profiles (see

127 below for definition); and (d) duration of each diving bout.

128 2) Lateral close view: (a) stroke frequency of paddling - number of strokes performed 129 by one hind limb in 1 second during surface swimming; (b) inclination - the angle 130 maintained between the central long axis of the animal's body and the water line; (c)

131 duration of each floating bout; (d) duration of each diving bout; (e) the Fineness Ratio 132 maximum length to maximum height of the body (the measure of streamlining - Fish 133 1993b; Fig. 1) while swimming, diving and floating; and (f) the diving profiles (see 134 below).

135 3) Dorsal view: (a) width of body as compared to amplitude of tail beating - maximum 136 width of body to maximum amplitude of the tail beating at the same moment; (b) width of 137 the body as compared to its length.

138 Profiles. The diving profiles performed by shrews were classified according to 16 models (Fig. 2). These were a priori idealized according to four factors and a score was 140 given according to an assumed quantity of energy expended for each action ( 1 for lower or 1412 for higher energetic cost; for scores see Fig. 2): (a) descent angle - obtuse vs acute; (b) 142 depth of the dive - shallow (up to the half of the water depth, i.e. ca. $12 \mathrm{~cm}$ ) vs deep (more 143 than $12 \mathrm{~cm}$, usually to the bottom); (c) distance swum underwater reaching the deepest 144 point - short (up to $25 \mathrm{~cm}$ ) vs long (more than $25 \mathrm{~cm}$ ); and (d) ascent angle - obtuse vs 145 acute. The scores of each profile were added for these factors and three difficulty 146 categories were established: easy - total score of 4 or 5 (profiles P1-P5), medium - total 147 score of 6 (profiles P6-P11) and difficult - total score of 7 or 8 (P12-P16). The real dives of 148 water shrews, of course, did not have to start at left edge of aquarium (as shown in Fig. 2) 149 but could start at any point of water surface. Not only straight-line but also curve-line dives 150 were included into the analysis. 
152 underwent 3-gradual averaging: $1 \mathrm{st}^{\mathrm{o}}$ average was calculated for a given trial, $2 \mathrm{nd}^{\mathrm{o}}$ average

153 for each tested shrew (including up to 5 trials), and $3 \mathrm{rd}^{\mathrm{o}}$ average for species (up to 12

154 shrews). The $3 \mathrm{rd}^{\mathrm{o}}$ averages are shown in the table and figures, whereas the $2 \mathrm{nd}^{\mathrm{o}}$ averages

155 were used in statistical analyses as replications. This data manipulation was done in order

156 to reduce intra- and interindividual variation and avoid pseudo-replication.

157 Statistical analysis. Mann-Whitney $U$-test was used (with STATISTICA ver. 6) for 158 interspecific statistical comparisons of all behaviours except the diving profiles.

159 Distributions of frequencies of different types of profiles were compared by Kolmogorov160 Smirnov test (SYSTAT ver. 5; Sokal and Rohlf 1995). This informed us about the

161 significance of general differences between the species as well as differences between the

162 observed and expected distributions within each species. We assumed that the shrews

163 would not display preference for any particular profile, so the observed frequency would

164 be close to an expected uniform distribution with frequencies of each profile type $=6.25$

$165(100 \% \times 1 / 16=6.25)$. Replicated goodness-of-fit tests $(G$-statistic) $($ Sokal and Rohlf 1995$)$

166 were performed to compare the total number of dives and the number of difficult dives

167 performed by each species, as well as in pairwise comparisons of each diving profile.

168 Statistical significance was considered at $p<0.05$ (two-tailed). Some behaviours were not 169 displayed by or measurable in all tested animals, therefore the sample size $n$ differs usually 170 from 11 in N. anomalus and 12 in N. fodiens.

Ethical note

The animals were cared for in accordance with the Guidelines for the treatment of animals in behavioural research and teaching (Anonymous 2003). Pregnant and lactating

174 females (as well as other unwanted small mammals) were immediately released at the 175 place of capture. The duration of the tests (= 5-minute-recordings) was chosen after 176 considering the experiments performed by Vogel (1990), in which animals were forced to 
swim or dive for 6 minutes. The tests were carefully monitored and were stopped if any

178 animal showed an apparent difficulty in staying afloat. This happened to only one animal,

179 and when the experiment with this animal restarted the following day, the animal did not

180 show any signs of difficulty or extreme stress. None of the animals died during or directly

181 after a test. We have obtained permission (no. DLOPiKog. 4201-04-136/2001/2002 of 28

182 February 2002) from the Minister of Environment for our capturing of the protected

183 shrews and an acceptance (no. 2001/11 of 11 January 2001) from the Local Ethical

184 Commission for Experiments with Animals in Białystok (Poland) for our experimental 185 methods.

The proportions of different behaviours varied between the species (Fig. 3). Both species spent most of their time swimming (ca. $92 \%$ for $N$. anomalus and $80 \%$ for $N$. fodiens), but this time was significantly longer in $N$. anomalus than in N. fodiens (MannWhitney $U$-test: $U=6.0, p=0.003)$. Shrews swam all over the aquarium but preferred to stay near the walls and corners. The duration of floating did not differ between species ( $U$

$193=21.0, p=0.149)$. While floating the animals would scratch themselves, groom their fur

194 or look around the aquarium. The time spent diving was significantly $(U=4.0, p=0.002)$ shorter in $N$. anomalus than $N$. fodiens.

Surface behaviours

The speed of surface swimming did not differ significantly between species $(U=$ $19940.0, p=0.965$; Table 1), but the stroking frequency of paddling was higher in $N$. anomalus than $N$. fodiens $(U=22.5, p=0.013)$. The animals paddled with an alternate stroking of the front and hind limbs on a transverse plane. The inclination of swimming animals from horizontal was quite low for both species and did not differ significantly $(U=$ 
$36.0, p=0.305)$. In both species the nose and head were always just above the water

204 surface and the tail undulated on or near the surface (Fig. 1). The ratio of the maximum

205

206

207

208

209

210

211

212

213

214

215

216

217

width of the body to the maximum amplitude of the tail movement was significantly higher in $N$. fodiens than in $N$. anomalus $(U=3.0, p=0.004)$, indicating that $N$. fodiens performed narrower movements with the tail. However, $N$. fodiens had a significantly wider body $(U=3.0, p=0.004)$ in comparison to $N$. anomalus .

The mean duration of single floating bouts was significantly longer in $N$. fodiens than in $N$. anomalus $(U=12.0, p=0.012$; Table 1$)$. To float, the animals would project their limbs downwards and their body would be less stretched; the tail appeared to float without any active effort from the animal. The Fineness Ratio (FR) while floating was quite low for both species (Table 1) and no significant interspecific difference existed $(U=$ 17.0, $p=0.855$ ). Also when swimming, the FR did not differ significantly between the species $(U=51.0, p=0.356)$.

\section{Diving behaviour}

The interspecific differences while diving were more distinct than for surface behaviours. The mean duration of single diving bouts was significantly longer in N. fodiens than in $N$. anomalus $(U=9.0, p=0.003$; Table 1$)$. The FR of diving shrews was significantly higher in $N$. anomalus than $N$. fodiens $(U=10.0, p=0.001)$. In both species, the FR increased in the following order: floating $<$ swimming $<$ diving (Table 1), and all pairwise intraspecific differences between $\mathrm{FR}_{\text {floating }}, \mathrm{FR}_{\text {swimming }}$ and $\mathrm{FR}_{\text {diving }}$ were significant ( $U=$ from 0.0 to 25.0 and $p=$ from 0.001 to 0.012 ).

The total number of dives displayed by 12 individuals of $N$. fodiens was 4 times 226 higher than that displayed by 11 individuals of $N$. anomalus ( 758 vs 183, Fig. 4; this gives 63.2 vs 16.6 dives/individual, Replicated goodness-of-fit tests: $G=29.02, p<0.001)$. The 
interspecific difference was much higher when the number of difficult dives only (profiles P13, P14, P15, P16) was compared: it was 10 times higher in $N$. fodiens than N. anomalus (453 vs 42 difficult dives or 37.8 vs 3.8 difficult dives/individual, $G=32.24, p<0.001$ ). not differ significantly between the two species (Kolmogorov-Smirnov test: $D=0.188, p$ $=0.895)$. However, these distributions were very different from the expected uniform distribution $(D=0.688, p<0.001$ for $N$. anomalus; $D=0.875, p<0.001$ for $N$. fodiens $)$, indicating that both species displayed some preferences.

$237=5.538$ to $40.108, p<0.025$ to 0.001$) ; N$. anomalus preferred additionally P8 $(G=8.699$, $p<0.005)$ and tended to prefer $\mathrm{P} 2(G=3.544, p<0.1$; Fig. 4). The preferred profiles (P8+P10+P15) constituted 59.0\% (73.8\% including $\mathrm{P} 2)$ of all diving profiles performed by N. anomalus and $72.3 \%(\mathrm{P} 10+\mathrm{P} 15)$ in $N$. fodiens. $N$. anomalus performed the easy profile P2 and the medium difficulty profile P8 significantly more frequently than $N$. fodiens $(G=$ $6.199, p<0.025$ and $G=9.886, p<0.005$, respectively). In contrast, $N$. fodiens performed the difficult profile P15 much more frequently than $N$. anomalus $(G=17.276, p<0.001)$. While swimming on the bottom, $N$. fodiens stopped and changed the swimming direction much more frequently than $N$. anomalus.

The common profiles avoided by the two species were all shallow and usually long 247 dives P4, P7, P9, P11, and P12 ( $G=4.001$ to $8.664, p<0.05$ to 0.005 ; Fig. 4). 248 Additionally, N. anomalus avoided P13 and P16 $(G=5.619, p<0.025$ in both cases $)$ and $249 N$. fodiens avoided P1 $(G=5.683, p<0.025)$. The avoided profiles constituted $2.7 \%$ and $2501.7 \%$ of the total diving profiles observed in $N$. anomalus and $N$. fodiens, respectively. $N$. anomalus never performed 3 out of the 16 profiles (P4, P7, P12), whereas $N$. fodiens only one (P12). Moreover, N. anomalus avoided three types of difficult profiles (P12, P13, P16), whereas N. fodiens only one (P12). 


\section{Discussion}

Both species spent most of their time in the aquaria swimming on the surface and frequently tried to leave water at the corners of aquaria. Possibly the shrews did not feel comfortable under the experimental conditions (open water surface, no firm ground to rest) and their behaviour could be influenced by stress. These conditions prevented also the shrews from spontaneous swimming and did not give them motives (aquatic prey) for 260 diving. However, the most important fact is that both studied species underwent the same experimental conditions and displayed a list of significant interspecific differences (in 6 out of 10 compared parameters plus differences in diving profiles). And we were interested in these differences rather than whether the behaviour observed in our aquaria mirrored the behaviour of water shrews in the wild. Moreover, in the present study, we were interested only in mechanistic differences in swimming and diving, not in the motives or results of such behaviours. Differences between $N$. anomalus and $N$. fodiens in terrestrial and underwater exploring and foraging (especially the higher success and effectiveness in underwater foraging of $N$. fodiens) under conditions giving shrews many motives, stimuli and opportunity for spontaneous swimming and diving have been already known (Rychlik 1997).

The alternate stroke of the front and hind limbs on a transverse plane was observed in both species. It is considered as an efficient way of swimming (Hickman and Machiné 1986), however, such quadrupedal paddling is less effective than alternate bipedal paddling of hind limbs, typical for most well-adapted semiaquatic mammals (Fish 1993a, b). The swimming velocities of the studied species were not significantly different from one another. This is in contrast to our prediction, since the hind feet (the main propulsive power of water shrews) are longer, the fringes denser and longer, and consequently the paddling surface is larger in $N$. fodiens (Pucek 1981). However, this discrepancy could be readily explained by differences in the stroking frequency of paddling: $N$. anomalus, with a 
smaller paddling surface, had to stroke more frequently $(8.22 \mathrm{str} / \mathrm{s}$ vs $7.56 \mathrm{str} / \mathrm{s})$ to reach

281 the same velocity as $N$. fodiens. Unfortunately, we were not able to determine the stroke 282 frequency while diving from our recordings.

The swimming velocities measured in our study $(36.4 \mathrm{~cm} / \mathrm{s}$ in $N$. fodiens and 33.4

$\mathrm{cm} / \mathrm{s}$ in $N$. anomalus) are slightly lower than those recorded for $N$. fodiens previously (ca. $40 \mathrm{~cm} / \mathrm{s}$ - Ruthardt and Schröpfer 1985; 36.7-44.1 cm/s - Köhler 1991). This may result from the shorter aquarium used in our experiments $(100 \mathrm{~cm}$ compared to 300 and $145 \mathrm{~cm}$ in the two mentioned papers).

The tail of the two species undulates while swimming on the surface, which is an indication of good swimming skills (Cook et al. 2001). Like in other semi-aquatic mammals, e.g. the muskrat (Fish 1982, 1993b), the tail of water shrews is slightly flattened at the sides due to the keel of stiff hairs on the ventral side (Pucek 1981), and it moves synchronously with the strokes of the hind feet. This is believed to counter-balance the yawing that would be generated by the alternate stroking of the hind limbs, and therefore increases stability during swimming, reduces drag and allows the animals to present a more streamlined frontal view to the water flow (Fish 1982; Kryštufek et al. 2000). N. fodiens performed narrower movements with its tail (in relation to its body width) than $N$. anomalus. Apparently, thanks to the longer keel and its greater thrust generation, stable swimming was obtained by $N$. fodiens with a smaller amplitude of tail beats than in $N$. anomalus.

Both water shrew species swam in a similar, almost horizontal mode with their

301 nose near the water surface. Also, both species spent some time floating, with the total

302 duration of this behaviour being somewhat longer in N. fodiens than in N. anomalus. The mean duration of floating bouts was, however, significantly longer in $N$. fodiens than in $N$.

304 anomalus. This again suggests that $N$. fodiens is better adapted to water than $N$. anomalus.

305 This behaviour has not been described so far for these species. The animals apparently 
306 floated while resting or preparing for a dive. Floating, as well as swimming in a horizontal

307 position, can be attributed to high buoyancy (Fish 1993a), which in water shrews results

308 from large amounts of air trapped in their fur (Appelt 1973; Ivanter 1994). Horizontal

309 position and high buoyancy, in turn, can be considered an indication of good swimming

310 skills because paddling forces can be mostly used for propulsion and not wasted in

311 maintaining the head above the water level (Fish 1993a; Cook et al. 2001). This also shows

312 that morphological adaptations, especially those related to the insulating properties of the

313 fur, are very effective and important for the swimming behaviour of water shrews. These

314 adaptations allow the animals to save energy by reduction of heat loss (Vogel 1990;

315 Churchfield 1998) as well as by facilitation of floating and returning to the water surface

316 after diving. However, a high buoyancy also increases the energy costs of paddling

317 downwards and remaining submerged in the water column.

318 The duration of single dives by $N$. fodiens, registered in different studies, varied

319 from 3 to 16 seconds in laboratory conditions, and from 3 to 24 seconds in the wild

320 (Churchfield 1998; Vogel et al. 1998). In our experiments, $N$. fodiens spent on average 3

321 seconds and $N$. anomalus 2 seconds under water (with a maximum of 4 and 2.3 seconds,

322 respectively). Although these results can be influenced by size of the aquarium and lack of

323 prey, the most important observation is that the mean duration of diving bouts, as well as

324 the total time spent diving and total number of dives performed, were longer/higher in $N$.

325 fodiens than in $N$. anomalus. These results are consistent with our prediction and, together

326 with interspecific differences in morphological adaptations, may explain why $N$. fodiens

327 forages more efficiently in deep water (Rychlik 1997) and eats more aquatic prey

328 (Churchfield and Rychlik 2006). N. anomalus seems to forage by wading in shallow water

329 (Rychlik 1997, 2000; Churchfield and Rychlik 2006) and it may dive to explore the

330 environment or to escape from predators rather than to forage.

331 The Fineness Ratio (a measure of streamlining - Fish 1993b) of both water shrews 
332 increased in the following order: floating $<$ surface swimming $<$ diving, which is logical

333 since the benefit of streamlining increases in the same order. Moreover, compression and

334 loss of air bubbles from the fur during deep diving enhance the streamlining of these species. While swimming and diving, both species had FRs (3.19 to 3.85) within the range of favourable values (3 to 7 - Fish 1993b). Nevertheless, these values were lower than the most optimal FR=4.5 (Fish 1993b). However, such optimal values are observed in aquatic

338 mammals, especially in pursuit-type predators like dolphins and seals (Fish 1993b).

339 Semiaquatic water shrews do not pursue their prey underwater, so their FR can be lower.

340 On the other hand, the fact that during diving $N$. anomalus was flatter $(\mathrm{FR}=3.85)$ than $N$.

341 fodiens (3.55) can be explained by different diving modes. $N$. fodiens dived mostly along

342 the bottom (P15) and frequently changed direction, stopped, and shrank or bent its body at

343 the bottom irregularities. In contrast, $N$. anomalus dived more in open water (P2, P8, P10)

344 and its body was usually stretched in straight-line movement. Another cause can lay in a

345 difference in fur quality: possibly less air was retained in the fur of $N$. anomalus than $N$. 346 fodiens.

Both species preferred the deep profiles P10 (of medium difficulty) and P15

348 (difficult), but $N$. fodiens performed P15 more frequently than N. anomalus. $N$. anomalus

349 performed P2 (shallow and easy) and P8 (of medium difficulty) more frequently than $N$.

350 fodiens. Similarly, in the experiment of Haberl (1993), dives to the bottom of aquarium

351 amounted up to $2 \%$ in $N$. anomalus, whereas $40 \%$ in $N$. fodiens. Generally, in our study the

352 diving profiles performed by $N$. fodiens were more variable and this species avoided (never

353 performed) only one difficult profile. N. anomalus never performed three profiles and

354 avoided three difficult ones, indicating that adaptation for diving is lower in this species.

355 However, more detailed experiments utilizing larger tanks (with shallow and deep water

356 compartments and the presence of benthic and pelagic prey) would be useful to further

357 examine the diving abilities of each species. Additional studies examining the 
358 physiological attributes (i.e. blood and muscle oxygen carrying capacity and aquatic

359 thermoregulatory abilities) of both species may also prove insightful.

360 Nevertheless, the results of the present study are very helpful in understanding the

361 field observations: $N$. fodiens prefers sites with direct access to streams and deep water,

362 whereas $N$. anomalus prefers places with shallow water some distance from the stream

363 (Rychlik, 2000). In the wild, aquatic prey compose usually $\geq 50 \%$ of the diet of $N$. fodiens

364 (Churchfield 1984; Kuvikova 1985b) and may reach 95\% (Niethammer 1978; DuPasquier

365 and Cantoni 1992). In contrast, the diet of $N$. anomalus may be composed mostly of 366 terrestrial prey (Niethammer 1978; Kuvikova 1987; Churchfield and Rychlik 2006) or only

367 of terrestrial prey (Kuvikova 1985a; Ramalhinho 1995). In laboratory experiments with 368 shallow water $(3.5 \mathrm{~cm}), N$. anomalus captured many aquatic prey (fish, crustaceans) and 369 utilised them in similar quantities to N. fodiens (Rychlik and Jancewicz 2002). However, in 370 experiments with deep water $(>10 \mathrm{~cm}), N$. fodiens found and took food, whereas $N$. anomalus dived significantly shorter than $N$. fodiens and did not take food placed in such water (Rychlik 1997). Thus, $N$. fodiens is able to forage both in deep and shallow water, while N. anomalus can only forage successfully in shallow water (Rychlik 1997, 2000). All

374 these observations are consistent with the results of the present study that demonstrates for 375 the first time qualitatively and quantitatively the differences between $N$. fodiens and $N$. anomalus in swimming and diving abilities. These differences, in turn, may correlate with

377 the different foraging modes used mainly by the two species: wading by N. anomalus and 378 diving by $N$. fodiens. Similar differences in swimming and diving abilities have been found 379 in rodents and attributed to the separation of their niches (e.g. Esher et al. 1978; Cook et al. 380 2001). We can thus conclude that the differentiation in diving abilities and foraging modes may be one of the behavioural mechanisms that allow these two species of water shrews to partition resources and segregate their ecological niches, and in consequence to co-exist syntopically. 
We are very grateful to R. Schröpfer and A. Schwegmann for access to apparatus and lab, and their help in Osnabrück; to S. Carvalho and M. Simões for their field and technician assistance; to J.R.E. Taylor and G. Ramalhinho for stimulating discussions; and to H. Cabral for help in the statistical analysis. P. Redman kindly improved our English. This study was financed by the Leonardo da Vinci Programme (Agreement no P/03/A/F/PL - 125809), the Polish State Committee for Scientific Research (research grant No 6 P04F 036 21) and Centre of Excellence BIOTER (Contract No EVK2-CT-2002-80011, European Commission's 5th

392 Framework Programme).

393

394

395

396

397

398

\section{References}

Anonymous (2003) Guidelines for the treatment of animals in behavioural research and teaching. Anim Behav 65:249-255

Appelt H (1973) Fellstrukturuntersuchungen an Wasserspitzmäusen (Neomys fodiens (Pennant)). Abh Ber Naturk Mus “Mauritianum” 8:81-87

Biewener AA (2003) Animal locomotion. Oxford University Press, Oxford

Churchfield S (1984) Dietary separation in three species of shrews inhabiting water-cress beds. J Zool 204:211-228

Churchfield S (1998) Habitat use by water shrews, the smallest of amphibious mammals. In: Dunstone N, Gorman ML (eds) Behaviour and ecology of riparian mammals. Cambridge University Press, Cambridge, pp 49-68

Churchfield S, Rychlik L (2006) Diets and coexistence in Neomys and Sorex shrews in Białowieża Forest, eastern Poland. J Zool 269:381-390

Cook WM, Timm RM, Hyman DE (2001) Swimming ability in three Costa Rican dry forest rodents. Rev Biol Trop 49:1101-1104

DuPasquier A, Cantoni D (1992) Shifts in benthic macroinvertebrate community and food habits of the water-shrew, Neomys fodiens (Soricidae, Insectivora). Acta OEcol, OEcol General 13:81-99

Esher RJ, Wolfe JL, Layne JN (1978) Swimming behavior of rice rats (Oryzomys palustris) and cotton rats (Sigmodon hispidus). J Mammal 59:551-558 
414 Fish FE (1982) Function of the compressed tail of surface swimming muskrats (Ondrata 415 zibethicus). J Mammal 63:591-597

416 Fish FE (1993a) Comparison of swimming kinematics between terrestrial and semiaquatic 417 opossums. J Mammal 74:275-284

419 Fish FE (1993b) Influence of hydrodynamic design and propulsive mode on mammalian swimming energetics. Aust J Zool 42:79-101

421 Haberl W (1993) Zur Ökologie einheimischer Spitzmäuse (Soricidae, Insectivora) und ihres

422 Lebensraumes am Beispiel eines Waldviertler Feuchtbiotops und experimentelle Bearbeitung 423 ausgewählter ethologischer Fragestellungen.) Dissertation, University of Vienna, Vienna, pp $424265+$ Appendix pp 211

426 Hickman GC, Machiné C (1986) Swimming behavior in six species of African rodents

427 (Cricetidae, Muridae). Acta Theriol 31:449-466

428

429 Hutterer R (1985) Anatomical adaptations of shrews. Mammal Rev 15:43-55

431 Ivanter EV (1994) The structure and adaptive peculiarities of pelage in soricine shrews. In: 432 Merritt JF, Kirkland GLJr, Rose RK (eds) Advances in the biology of shrews. Special 433 Publication of Carnegie Museum of Natural History No. 18, Pittsburgh, pp 441-454

434 Köhler D (1991) Notes on the diving behavior of the water shrew, Neomys fodiens 435 (Mammalia, Soricidae). Zool Anz 227:218-228

436 Köhler D (1993) On the learning of the position of underwater food sources by Neomys

437 fodiens (Mammalia, Soricidae). Zool Anz 231:73-81

439 Köhler D (1996) Umwegversuche mit tauchenden Wasserspitzmäusen (Neomys fodiens)

440 (Mammalia: Soricidae). Bonn Zool Beitr 46:315-325

442 Kryštufek B, Davison A, Griffiths HI (2000) Evolutionary biogeography of water shrews 443 (Neomys spp.) in the western Palaearctic Region. Can J Zool 78:1616-1625

444 Kuvikova A (1985a) The food of some species of the family Soricidae (Insectivora) in the 445 alder forest of the Jursky sur wetland. Biológia 40:181-187 [In Slovak with English abstract] 
446 Kuvikova A (1985b) Zur Nahrung der Wasserspitzmaus, Neomys fodiens (Pennant, 1771) in

447 der Slowakei. Biológia 40:563-572

448 Kuvikova A (1987) Zur Nahrung der Sumpfspitzmaus, Neomys anomalus Cabrera, 1907

449 (Insectivora, Soricidae) in der Slowakei. Lynx 23:55-62

450

451 Niethammer J (1978) Weitere beobachtungen über Wasserspitzmäusse der Arten Neomys 452 fodiens und N. anomalus. Z Säugetierk 43:313-321

453 Pucek Z (ed) (1981) Keys to vertebrates of Poland. Mammals. PWN - Polish Scientific 454 Publishers, Warszawa

455 Ramalhinho MG (1995) Preliminary account of the biology of Neomys anomalus Cabrera, 4561907 in Portugal. In: Proceedings of the "Seminar on the biology and conservation of 457 European desmans and water shrews (Galemys pyrenaicus, Desmana moschata, Neomys 458 spp.)”, Ordesa, Spain, 7-11 June 1995. Council of Europe, Strasbourg, T-PVS (95) 32:63-66

459 Ruthardt M, Schröpfer R (1985) Zum Verhalten der Wasserspitzmaus Neomys fodiens 460 (Pennant, 1771) unter Wasser. Angew Zool 72(1-2):49-57

461 Rychlik L (1997) Differences in foraging behavior between water shrews: Neomys anomalus 462 and Neomys fodiens. Acta Theriol 42:351-386

463 Rychlik L (2000) Habitat preferences of four sympatric species of shrews. Acta Theriol 45, 464 Suppl 1:173-190

465 Rychlik L (2004) Competition and coexistence of shrews. In: Jędrzejewska B, Wójcik JM 466 (eds) Essays on mammals of Białowieża Forest. Mammal Research Institute, Polish Academy 467 of Sciences, Białowieża, pp 161-170

468 Rychlik L (2005) Overlap of temporal niches among four sympatric species of shrews. Acta 469 Theriol 50:175-188

470 Rychlik L, Jancewicz E (2002) Prey size, prey nutrition, and food handling by shrews of 471 different body sizes. Behav Ecol 13:216-223

472 Rychlik L, Zwolak R (2005) Behavioural mechanisms of conflict avoidance among shrews. 473 Acta Theriol 50:289-308 
474 Rychlik L, Zwolak R (2006) Interspecific behavioural domination among four sympatric 475 species of shrews. Can J Zool 84:434-448

476 Sokal RR, Rohlf FJ (1995) Biometry. The principles and practice of statistics in biological 477 research. WH Freeman and Company, New York

478 Spitzenberger F (1990) Gattung Neomys Kaup, 1829. In: Niethammer J, Kapp F (eds) 479 Handbuch der Säugetiere Europas. Band 3/1. Insektenfresser, Herrentiere. Aula-Verlag, $480 \quad$ Wiesbaden, pp 317-333

481 Spitzenberger F (1999) Neomys anomalus Cabrera, 1907. Neomys fodiens (Pennant, 771). In: 482 Mitchell-Jones AJ, Amori G, Bogdanowicz W, Kryštufek B, Reijinders PJH, Spitzenberger F, 483 Stubbe M, Thissen JB, Vohralik V, Zima J (eds) The atlas of European mammals. T and AD 484 Poyser Ltd, London, pp 58-61

485 Torre I, Tella JL (1994) Distribution of the Cabrera water shrew (Neomys anomalus) in 486 northeastern Spain. Z Säugetierk 59:282-288

487 Vogel P (1990) Body temperature and fur quality in swimming water-shrews Neomys fodiens 488 (Mammalia: Insectivora). Z Säugetierk 50:73-80

489 Vogel P, Bodmer C, Spreng M, Aeschimann J (1998) Diving capacity and foraging behaviour 490 of the water-shrew (Neomys fodiens). In: Dunstone N, Gorman ML (eds) Behaviour and 491 ecology of riparian mammals. Cambridge University Press, Cambridge, pp 31-47 
492 Table 1. Summary of differences between Neomys anomalus and N. fodiens in surface

493 swimming, floating and diving. Significance of the differences (revealed by Mann-Whitney

$494 U$-test): ns - insignificant, ${ }^{* *} p \leq 0.01, * * * p \leq 0.005, * * * * p \leq 0.001$. The sample size $n$

495 varies because particular parameters were not displayed by or measurable in all tested

496 animals.

497

\begin{tabular}{|c|c|c|c|c|c|c|}
\hline \multirow{2}{*}{ Parameter of behaviour } & \multicolumn{2}{|c|}{ N. anomalus } & \multirow{2}{*}{$\begin{array}{l}\text { Diffe- } \\
\text { rence }\end{array}$} & \multicolumn{2}{|c|}{ N. fodiens } & \multirow{2}{*}{$\begin{array}{l}\text { Signifi- } \\
\text { cance of } \\
\text { difference }\end{array}$} \\
\hline & mean $\pm \mathrm{SD}$ & $n$ & & mean $\pm \mathrm{SD}$ & $n$ & \\
\hline \multicolumn{7}{|c|}{ Swimming } \\
\hline Velocity $(\mathrm{cm} / \mathrm{s})$ & $33.36 \pm 1.35$ & 9 & $=$ & $36.44 \pm 2.34$ & 9 & ns \\
\hline Stroking frequency (str./s) & $8.22 \pm 0.47$ & 10 & $>$ & $7.56 \pm 0.61$ & 11 & $* *$ \\
\hline Inclination $\left({ }^{\circ}\right)$ & $12.02 \pm 2.25$ & 11 & $=$ & $12.64 \pm 1.09$ & 9 & ns \\
\hline Body width : tail width ratio & $1.09 \pm 0.04$ & 8 & $<$ & $1.13 \pm 0.06$ & 7 & $* * *$ \\
\hline Body width : body length ratio & $0.36 \pm 0.01$ & 8 & $<$ & $0.39 \pm 0.01$ & 7 & $* * *$ \\
\hline Fineness Ratio & $3.19 \pm 0.339$ & 11 & $=$ & $3.26 \pm 0.310$ & 11 & ns \\
\hline \multicolumn{7}{|c|}{ Floating } \\
\hline Duration of single bout (s) & $1.28 \pm 0.32$ & 9 & $<$ & $2.00 \pm 0.74$ & 9 & $* *$ \\
\hline Fineness Ratio & $2.02 \pm 0.178$ & 5 & $=$ & $2.05 \pm 0.197$ & 6 & ns \\
\hline \multicolumn{7}{|c|}{ Diving } \\
\hline Duration of single bout (s) & $2.12 \pm 0.55$ & 9 & $<$ & $3.08 \pm 0.56$ & 9 & $* * *$ \\
\hline Fineness Ratio & $3.85 \pm 0.17$ & 10 & $>$ & $3.55 \pm 0.16$ & 12 & $* * * *$ \\
\hline
\end{tabular}




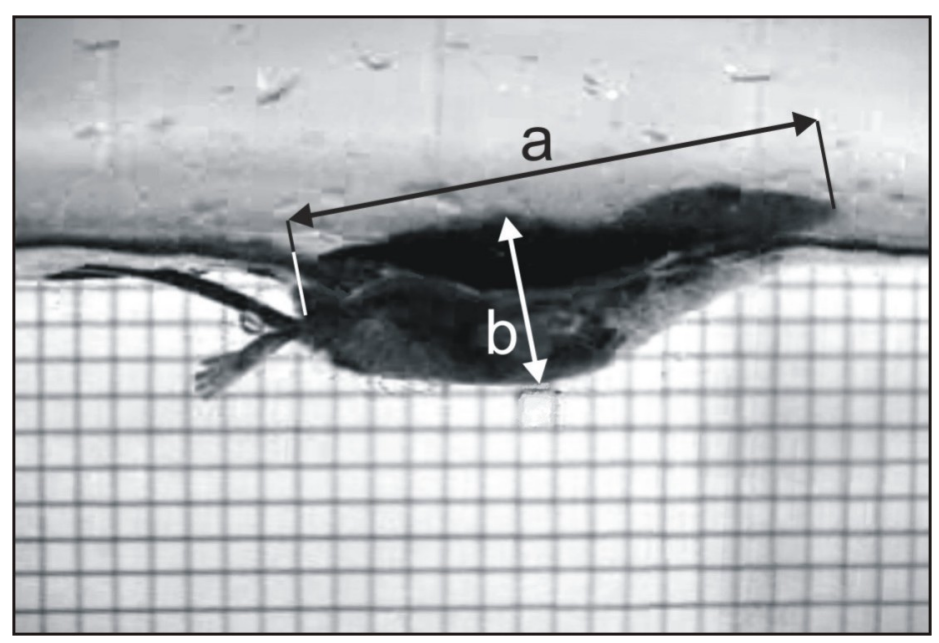

498 Fig. 1. Neomys fodiens swimming at the water surface. Measurements for the Fineness Ratio calculation $(F R=a / b)$ and the position of nose are visible. 


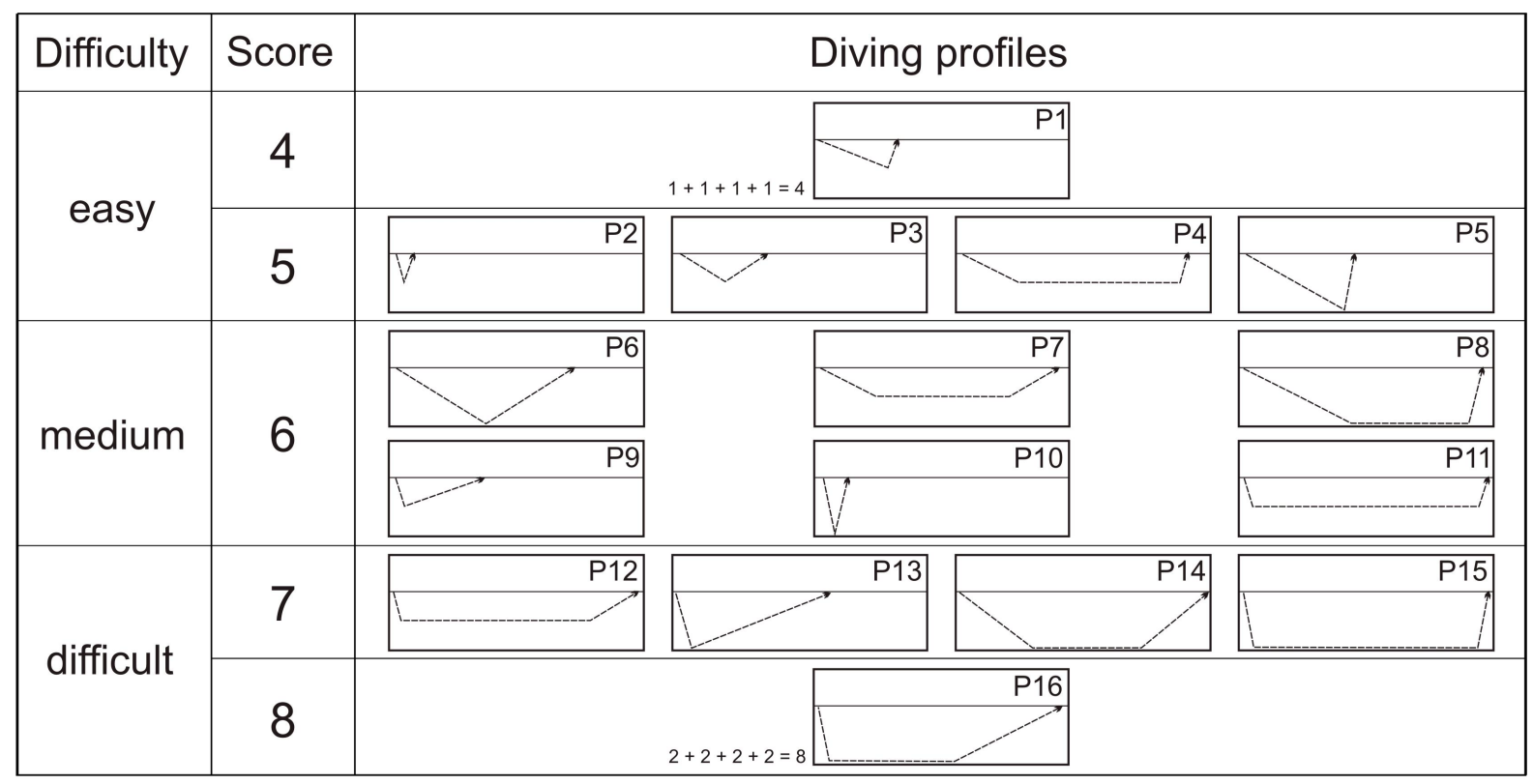

501 Fig. 2. Sixteen diving profiles distinguished in this study and ordered according to their 502 difficulty (scores from 4 to 8 ). 


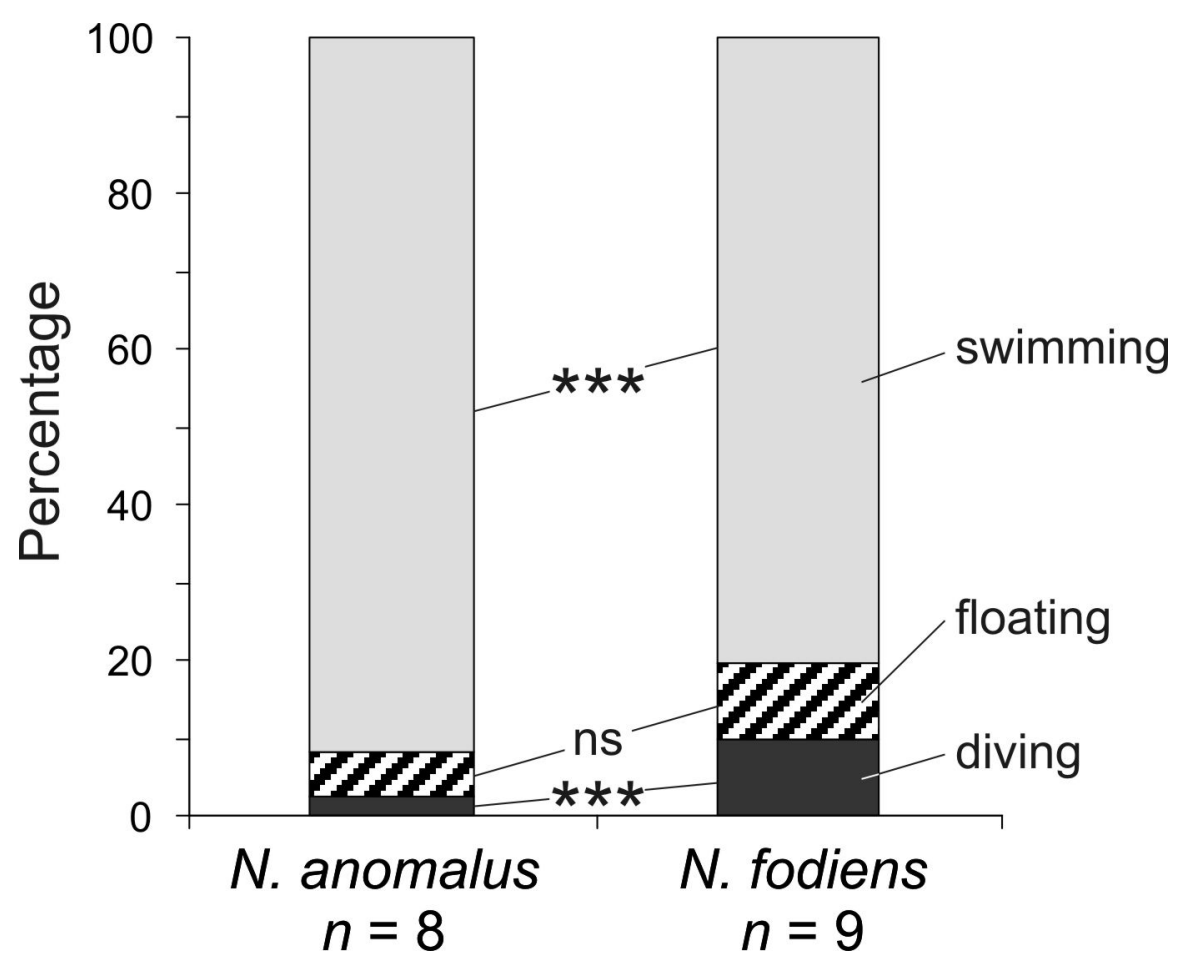

504 Fig. 3. Proportions of floating, swimming and diving displayed by the two species of Neomys

505 during the total time of a test. $100 \%=5$ minutes, $n$ - number of water shrews that displayed

506 all three kinds of behaviour. Significance of the differences (revealed by Mann-Whitney $U-$

507 test): $\mathrm{ns}-$ insignificant, $* * * p \leq 0.005$. 

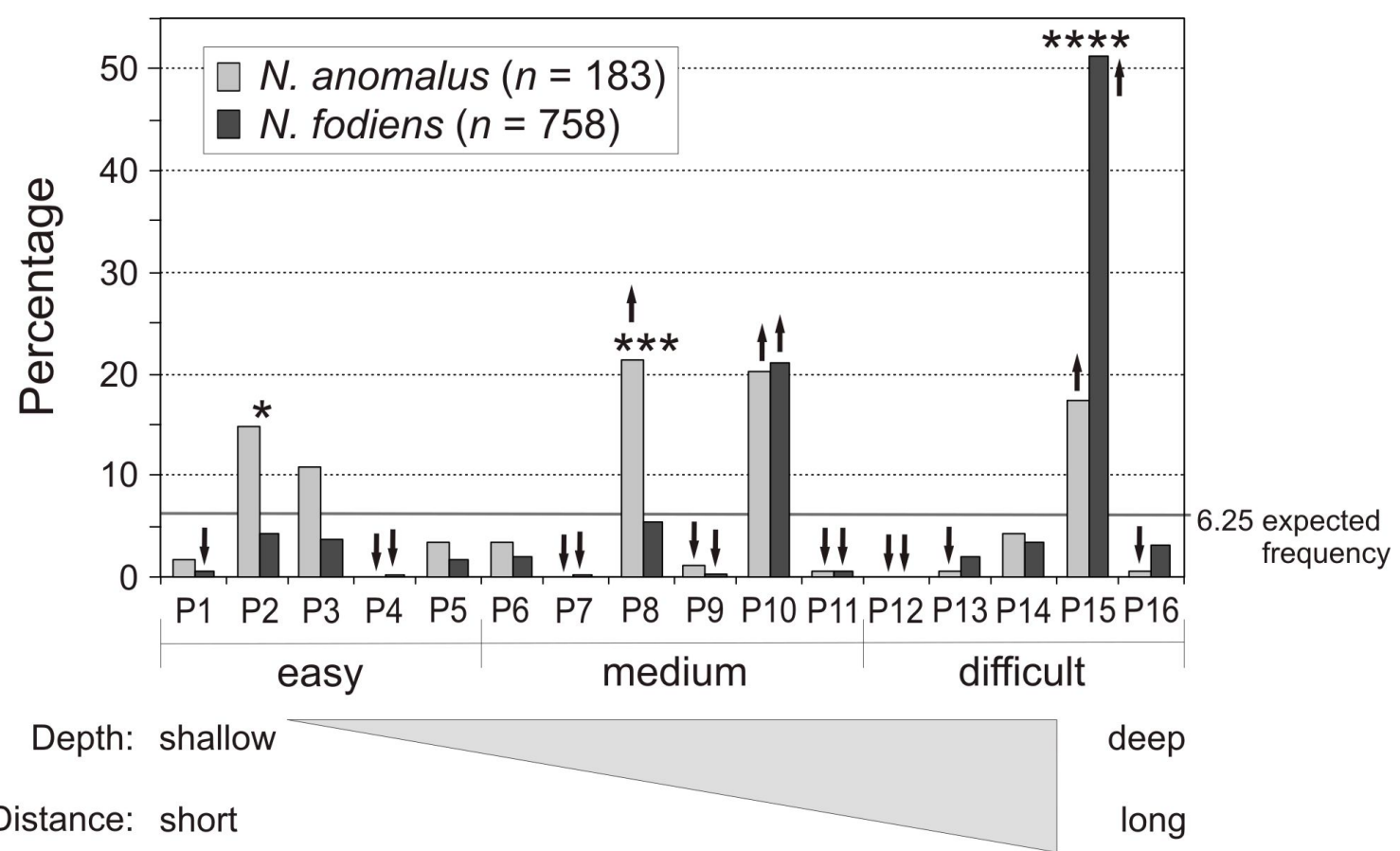

Descent angle: obtuse $-----------------------\cdot$ acute Ascent angle: acute $---------------------\cdot$ obtuse

509 Fig. 4. Differences in diving profiles between Neomys anomalus and N. fodiens. Significance

510 (revealed by goodness-of-fit $G$-test) of interspecific differences: ${ }^{*} p \leq 0.05, * * * p \leq 0.005$,

$511 * * * * p \leq 0.001$; differences between expected and observed values: arrow up - preferred

512 profile (significantly more frequent than expected), arrow down - avoided profile

513 (significantly less frequent than expected). 